\title{
SOCIAL ORGANIZATION OF LEPTOTHORAX ACERVORUM FROM ALASKA (HYMENOPTERA: FORMICIDAE)
}

\author{
By JÜRgen HeInZE AND Diethe OrTIUS
}

Zool. Inst. II, Röntgenring 10, 8700 Würzburg, F.R.G.

\section{INTRODUCTION}

Only very few ant species live in subarctic and alpine biomes near the tree-line, and surprisingly little is known about how they succeed in these habitats under extremely adverse environmental conditions. Recently it has been suggested that adoption of young queens, facultative polygyny, and colony budding might facilitate colony founding in areas with short summers and long winters (Heinze 1991).

Among the ants ranging farthest north both in Eurasia and North America is the small myrmicine Leptothorax acervorum (Arnoldi 1968, Collingwood 1979, Nielsen 1987). Individual colonies may contain several inseminated female reproductives. Populations from northern and central Europe are facultatively polygynous (i.e., several mated queens may reproduce within a single nest; Buschinger 1968, Douwes et al. 1987, Stille et al. 1991). Nests sampled in Furano in northern Japan, on the other hand, typically contained only one primary egg-layer, whereas additional inseminated gynes were ovipositing at a low rate or not at all (Ito 1990). This latter type of social organization, functional monogyny (Buschinger 1968), has been shown to result from aggressive competition among potential egg-layers in two other Leptothorax (s.str.) species (Heinze 1990, Heinze and Smith 1990, Heinze and Lipski 1990). Queens in polygynous nests of European L. acervorum do not show any overt antagonism towards each other (Bourke 1991).

Nothing is known about colony and population structure of $L$. acervorum in North America. We here report first data on colony composition and behavior of female reproductives in L. acervorum from shrub tundra habitats in Denali National Park, Alaska.

${ }^{*}$ Manuscript received 3 September 1991. 


\section{Material AND Methods}

Complete colonies of Leptothorax (s.str.) were collected in Alaska in August and September 1990 by one of us (D. O.) and K. Lechner by means of an aspirator, and transferred to the laboratory in $1.8 \mathrm{ml}$ polypropylene vials with perforated lids. In the laboratory, ants were kept in incubators at artificial temperature and light cycles (Buschinger 1974) and provided with diluted honey and pieces of cockroaches three times a week. Colonies were housed in three-chambered plastic boxes with a piece of cardboard and a microscopic slide separated by a perspex frame serving as nest (modified after Buschinger 1973; Fig. 1).

Female reproductives were individually marked with $0.02 \mathrm{~mm}$ platinum wire placed around the pedicel. Interactions were observed for appr. 16 hours using dissecting microscopes and an event-recording computer program by D.S. Gladstein (Carlin et al. 1987). We noted behavioral status of all females at irregular intervals, and additionally recorded all observed interactions among queens and other individuals.

After the behavioral observations, individuals were dissected following the method described by Buschinger and Alloway (1978).

Throughout this paper, a functional terminology is used. The term "queen" is thus applied only to denote functional queens, i.e. mated egg-layers. Female sexuals of unknown reproductive status are referred to as "gynes".

\section{RESULTS}

Among the 30 collected colonies of Leptothorax (s.str.), nine belong to $L$. acervorum (all from Wonder Lake, Denali N.P.). The remaining specimens can be classed with two or perhaps three species of the Leptothorax "muscorum" complex (Brown 1955, Heinze 1989; Tab. 1). Erect or semi-erect hairs are less abundant on scapes and legs of Alaskan $L$. acervorum than in specimens from Europe (comparison with samples from Sweden, Italy, Germany), but differ little from $L$. acervorum collected in Alaska by M.G. Nielsen.

Nests of L. acervorum were found in a subarctic birch and spruce forest (altitude of $560 \mathrm{~m}$ ), on south-exposed slopes and on 

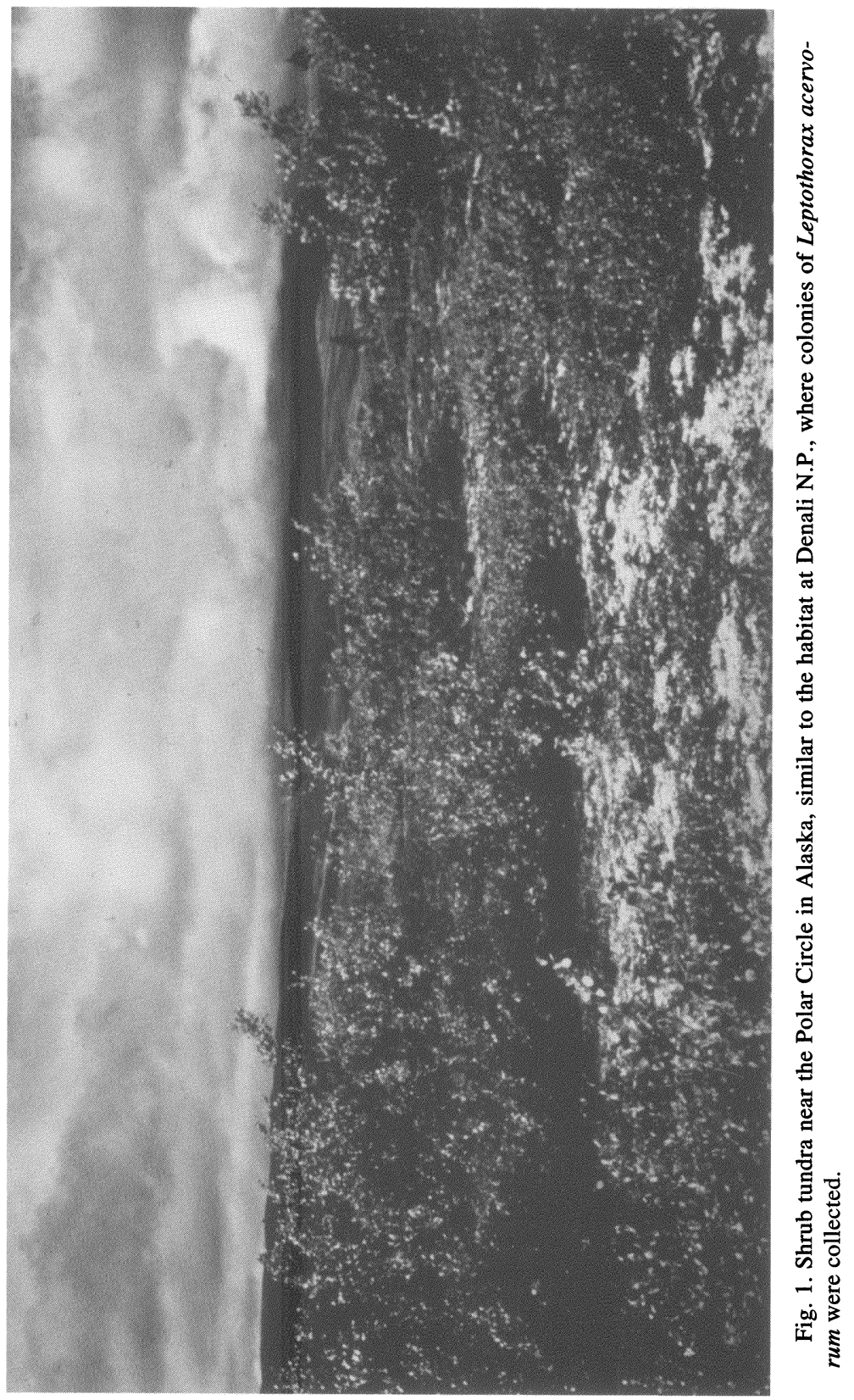


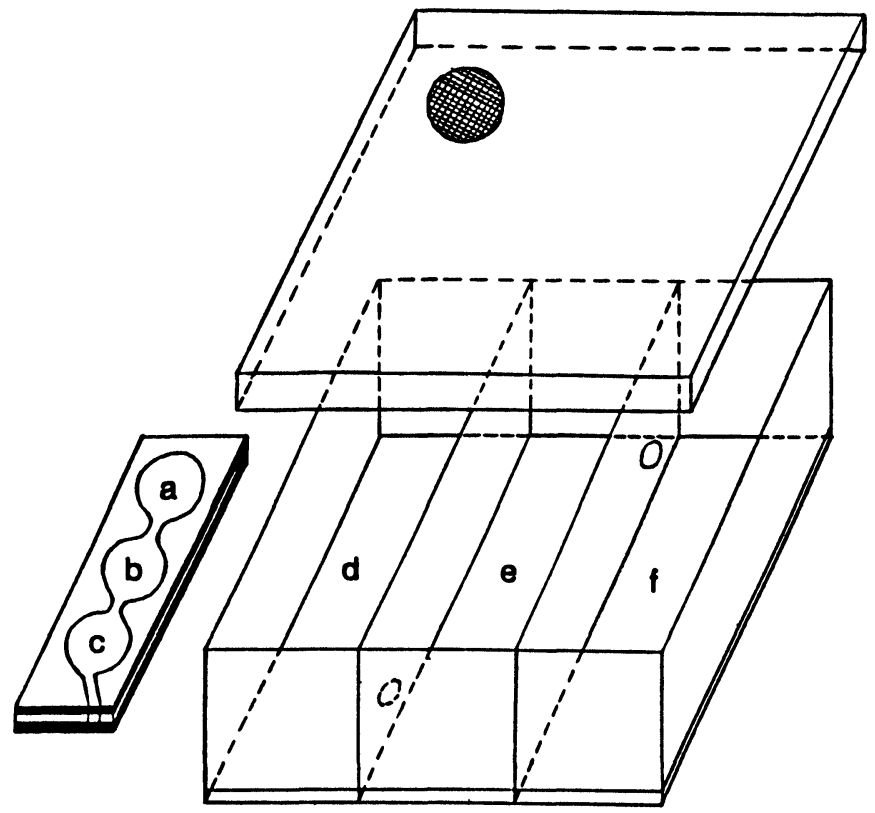

Fig. 2. Box for laboratory culture of leptothoracine ants (modified after Buschinger 1974). Food is provided in $\mathbf{f}$, water in $\mathbf{g}$. The nest consists of three compartments $(\mathbf{a}, \mathbf{b}, \mathbf{c})$ between a piece of cardboard and a glass lid, separated by a perspex frame

an even hill-top in a shrub tundra above the tree-line (altitude 700-800m; Fig. 2). Ants nested under flat slates and in rotting wood. Nest structures appeared similar to those from $L$. acervorum in Siberian mountain tundra (Zhigulskaya et al. 1980), with several chambers in the soil, ranging to a depth of approximately $5 \mathrm{~cm}$.

Four $L$. acervorum colonies from Denali N.P. contained several dealate female reproductives, two colonies were queenless, and three contained a single queen (Tab. 1). Dissections showed that most gynes were inseminated. In a colony with 16 dealate gynes, ovaries of at least six were markedly elongated and contained numerous corpora lutea and developing eggs, suggesting that several queens had been reproductively active. In three other colonies, two gynes each were found to be inseminated and their 
Table 1. Collecting sites and colony composition of Leptothorax (s.str.) from Alaska. If " $n$ " is printed in the table instead of queen or worker numbers, colonies were not censused. The taxonomic position of many nearctic Leptothorax (s.str.) is as yet not completely understood. We therefore refer to small brown or large black ants of the Leptothorax canadensis complex as L. spp. C and D (Heinze 1989).

\begin{tabular}{|c|c|c|c|c|}
\hline $\begin{array}{l}\text { Colony } \\
\text { number }\end{array}$ & $\begin{array}{l}\text { collecting } \\
\text { date }\end{array}$ & $\begin{array}{c}\text { site } \\
\text { altitude }\end{array}$ & species & $\begin{array}{c}\text { colony } \\
\text { composition } \\
\text { queens/workers }\end{array}$ \\
\hline ao 06 & Aug. 26, 1990 & Arctic Circle, $600 \mathrm{~m}$ & $\mathrm{D}$ & $2 / 40$ \\
\hline ao 07 & Aug. 26, 1990 & Arctic Circle, $600 \mathrm{~m}$ & $\mathrm{D}$ & $8 / \mathrm{n}$ \\
\hline ao 08 & Aug. 26, 1990 & Arctic Circle, $600 \mathrm{~m}$ & $\mathrm{D}$ & $3 / 35$ \\
\hline ao 09 & Aug. 26, 1990 & Arctic Circle, $600 \mathrm{~m}$ & D & $1 / \mathrm{n}$ \\
\hline ao 10 & Aug. 26, 1990 & Arctic Circle, $600 \mathrm{~m}$ & $\mathrm{D}$ & $4 / n$ \\
\hline ao 11 & Aug. 26, 1990 & Arctic Circle, $600 \mathrm{~m}$ & $\mathrm{D}$ & $2 / \mathrm{n}$ \\
\hline ao 12 & Aug. 26, 1990 & Arctic Circle, $600 \mathrm{~m}$ & $\mathrm{D}$ & $-/ 12$ \\
\hline ao 14 & Aug. 28, 1990 & Arctic Circle, $600 \mathrm{~m}$ & $\mathrm{C}$ & $\mathrm{n} / \mathrm{n}$ \\
\hline ao 15 & Aug. 28, 1990 & Arctic Circle, $600 \mathrm{~m}$ & $\mathrm{D}$ & $1 / \mathrm{n}$ \\
\hline ao 17 & Sept. 3,1990 & Denali N.P., 600m & $\mathrm{D}$ & $2 / 1$ \\
\hline ao 18 & Sept. 3,1990 & Mt. Healey, $1000 \mathrm{~m}$ & $\mathrm{D}$ & $1 / \mathrm{n}$ \\
\hline ao 20 & Sept. 8,1990 & Denali N.P., $560 \mathrm{~m}$ & L. $a c$. & $16 / 80$ \\
\hline ao 22 & Sept. 12,1990 & Denali N.P., $900 \mathrm{~m}$ & $\mathrm{D}$ & $\mathrm{n} / \mathrm{n}$ \\
\hline ao 23 & Sept. 12,1990 & Denali N.P., $800 \mathrm{~m}$ & L. $a c$. & $1 / 46$ \\
\hline ao 24 & Sept. 12,1990 & Denali N.P., $800 \mathrm{~m}$ & D & $4 / \mathrm{n}$ \\
\hline ao 25 & Sept. 12,1990 & Denali N.P., $800 \mathrm{~m}$ & L. $a c$. & $4 / 55$ \\
\hline ao 26 & Sept. 12,1990 & Denali N.P., $800 \mathrm{~m}$ & L. $a c$. & $2 / 27$ \\
\hline ao 27 & Sept. 12,1990 & Denali N.P., $800 \mathrm{~m}$ & D & $1 / \mathrm{n}$ \\
\hline ao 28 & Sept. 12,1990 & Denali N.P., $700 \mathrm{~m}$ & L. $a c$. & $-/ 13$ \\
\hline ao 29 & Sept. 13,1990 & Denali N.P., $700 \mathrm{~m}$ & L. $a c$. & $1 q /-$ \\
\hline ao 30 & Sept. 13, 1990 & Denali N.P., $700 \mathrm{~m}$ & L. $a c$. & $3 / 10$ \\
\hline ao 31 & Sept. 13,1990 & Denali N.P., $700 \mathrm{~m}$ & L. $a c$. & $1 / 40$ \\
\hline ao 32 & Sept. 13, 1990 & Denali N.P., $700 \mathrm{~m}$ & L. ac. & $1 / 24$ \\
\hline ao 33 & Sept. 13, 1990 & Deanli N.P., 700m & L. $a c$. & $-/ 12$ \\
\hline ao 34 & Sept. 13,1990 & Mt. Healey, $1330 \mathrm{~m}$ & D & $3 / 21$ \\
\hline
\end{tabular}

ovaries were more or less elongated and contained developing oocytes. However, from the absence of corpora lutea we conclude that none of these had laid eggs in the past.

Interactions among female reproductives were observed in two colonies, one with 16 gynes and 65 workers (colony ao20) and another with four gynes and 55 workers (colony ao25). In colony ao20 aggressive interactions among gynes were rare and when dissected, several gynes turned out to have laid eggs (see above). In colony ao25, on the other hand, three gynes engaged in aggressive 
Table 2. Aggressive interactions among dealate female reproductives in a colony of Leptothorax acervorum from Denali N.P., Alaska. Behaviors were observed for approximately 16 hours.

\begin{tabular}{|c|c|c|c|c|c|}
\hline \multicolumn{6}{|c|}{ attacked } \\
\hline attacker & a & $b$ & $\mathrm{c}$ & d & workers \\
\hline a & - & 17 & 6 & 0 & 62 \\
\hline b & 6 & - & 5 & 0 & 31 \\
\hline c & 0 & 1 & - & 0 & 2 \\
\hline d & 0 & 0 & 0 & - & 0 \\
\hline workers & 13 & 52 & 5 & 3 & 6 \\
\hline
\end{tabular}

interactions similar to those observed in functionally monogynous nests of Leptothorax sp.A and L. gredleri (Tab. 2).

During hibernation, most individuals in ao25 clustered around the brood. Gyne QB was occasionally observed sitting outside of the nest chamber, but had returned into the nest before we raised temperatures to spring conditions and started to monitor interactions.

During two weeks of observation, workers and brood were equally distributed in the nest chambers ( $a, b$ and $c)$, but gynes stayed separate from each other in different parts of the nest (Fig. 3 ). From the frequent exchange of places, it appears that segregation of gynes was caused by mutual avoidance rather than different spatial preferences. Indeed, encounters between gynes QA, QB, and occasionally also QC, regularly resulted in fights, ranging from unilateral antennation bouts and biting to mutual stinging attempts. Directly after the end of hibernation aggressive interactions among gynes were rare, but became more frequent and also more violent towards the end of our experiment. QD almost permanently stayed outside of the nest and never interacted with other gynes and rarely with workers, which she occasionally groomed or fed. She died four days after the beginning of spring, and was found to be uninseminated. QB and QC left the nest on day 3, probably as a consequence of several attacks by QA. Later on, QC was occasionally observed feeding and grooming workers or larvae. She was accidentally lost on day 11 and could not be dissected. Having no chance to escape from the laboratory arena, QB regularly returned into the nest, where encounters with QA became more and more pronounced. Workers had initially groomed and 


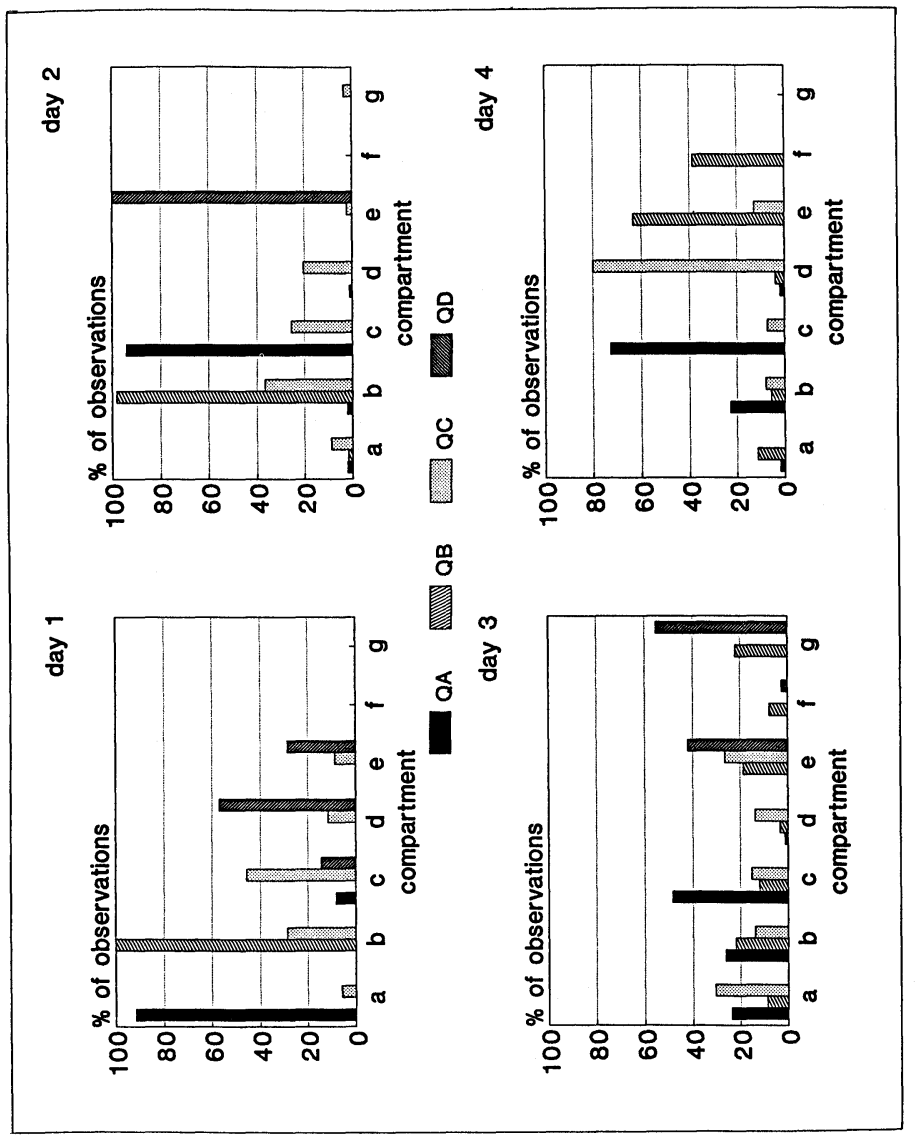

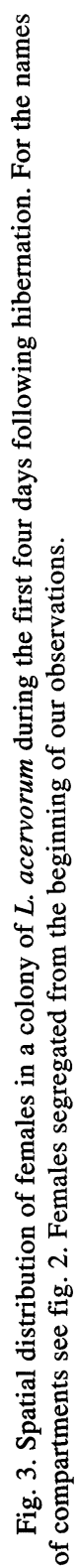


attacked QA and QB at similar rates, but after QB had left the nest, she was less and less frequently groomed, and more often attacked, while worker aggression towards QA ceased (Fig. 4).

Both gynes died during the third week of spring of unknown causes but probably as a consequence of prolonged fighting stress. Dissection showed that both were inseminated but had not yet laid eggs. The ovaries of QA were distinctly elongated and contained growing oocytes, those of QB were undeveloped.

For a detailed investigation of dominance and fighting behaviors, we blocked the nest entrance for about two hours, thus preventing the escape of gynes, and videotaped interactions, which later were analyzed frame by frame. During a typical episode, QA would move around in the nest with extended antennae and when encountering a nearby worker, either moved forward with open mandibles and briefly touched the other ant with her antennal clubs, or passed without visibly taking notice. When coming across QB, after brief antennation she immediately gripped one of QB's appendages with her mandibles and started to pull. QB initially crouched, retracted legs and antennae, or moved backwards, but within a few seconds regularly also started to bite. After short mandible fighting, both gynes bent their gasters underneath the thoraces with the tips pointing towards the opponent, as if attempting to sting. They tumbled about for a few seconds more, then parted abruptly and fled. In at least one interaction, the sting was visibly protruded shortly before fighting abruptly stopped.

Most assaults were initiated after short direct mutual antennal contact between the two combatants. However, in one interaction gyne QB appeared to casually touch one of QA's legs with her antenna. QA at once turned around, rushed at QB, antennated her back, and started to pull a leg, all within less than two seconds. In other cases, attacks were not preceded by visible tactile stimuli.

In colony ao20, aggressive interactions were only occasionally observed and consisted mostly of one queen heavily antennating head and thorax of an opponent.

\section{DISCUSSION}

Our results suggest that colonies of $L$. acervorum from forest tundra habitats in Denali N.P. in Alaska may contain several egglaying queens and thus are facultatively polygynous. However, 


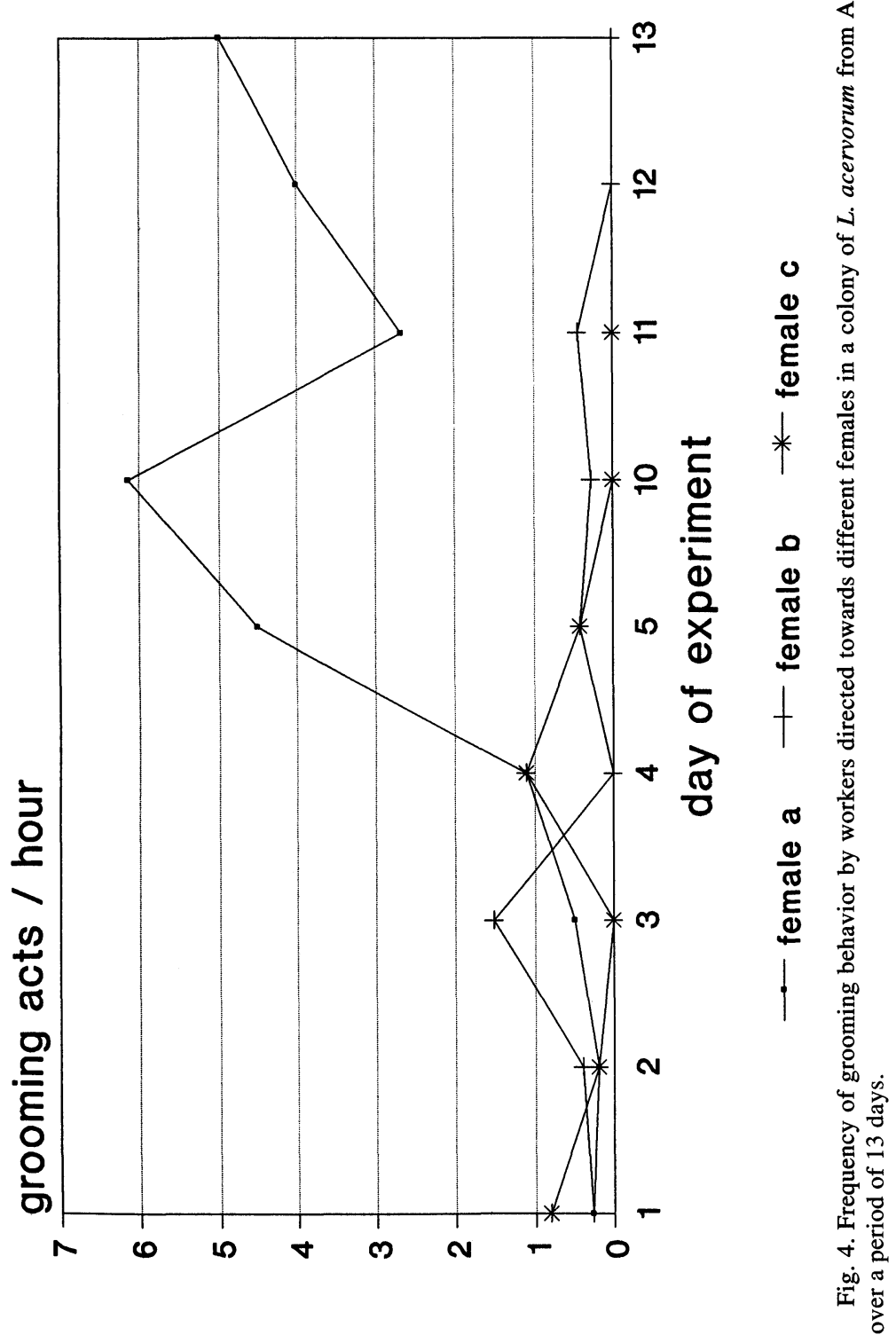


we also observed that fighting among nestmate queens may occur and that in this respect the Alaskan population is more similar to the functionally monogynous species Leptothorax gredleri and $L$. sp.A than to European $L$. acervorum. Our data do not suffice to decide whether functional monogyny or polygyny is the more common condition in the field. Colonies with multiple egg-laying queens have occasionally been found in functionally monogynous ants, e.g., Leptothorax sp.A (Heinze and Buschinger 1988), Formicoxenus nitidulus (Buschinger and Winter 1976), and F. diversipilosus (Buschinger 1979). Most of these exceptional finds have been explained by accidental mixing of two nests, but in other cases (e.g., Heinze and Smith 1990) it is more likely that reproductive dominance is not always absolute (see also Rissing and Pollock 1988). It therefore appears that polygyny and functional monogyny are not mutually exclusive but rather represent extremes in a continuous series of colony structures with varying degrees of queen tolerance, ranging from peaceful coexistence to total incompatibility.

The presence of openly aggressive competition among queens of $L$. acervorum from Alaska is not completely unexpected, as it may corroborate supposed correlations between social organization and habitat structure (Heinze, in prep.). A comparison of population and colony parameters of various leptothoracine ants suggests that functional monogyny occurs predominantly in species which live in patchily distributed habitats, such as spruce-bogs, rocky outcrops, or forest clearings, whereas true polygyny is common among species from extended, homogeneous areas (the significance of this correlation will be discussed elsewhere). In Europe and Siberia, Leptothorax acervorum is a wide-spread ant in boreal and alpine forests and moorlands (e.g., Collingwood 1979, Kutter 1975), and colonies may be polygynous. In contrast, populations in Alaska, and perhaps more generally in all subarctic North America, appear to be restricted to sunny patches, such as southfacing slopes, in forest and shrub tundras, where colonies locally occur at high densities (Gregg 1972, Francoeur 1983, Nielsen 1987). Similarly, colonies of the functionally monogynous $L$. acervorum in Japan predominantly occur on sunny patches and along woodpaths (Ito 1990). 
Fighting and dominance behaviors exhibited by potential queens of $L$. acervorum from Denali N.P. are similar to those observed in $L$. gredleri and $L$. sp.A (Heinze and Smith 1990, Heinze and Lipski 1990). Intensity of queen antagonism increased over the observation period; during the first hours of observation, gynes rarely interacted but segregated in different parts of the nest. Later, unilateral antennation bouts, biting, and pulling of antennae or legs became more frequent. Mutual stinging attempts were observed only towards the end of the experiment. The subordinate gyne QB spent a large part of observation time outside of the nest, and in the field would probably have tried to found her own colony in the vicinity instead of repeatedly returning into the old nest. The artificially prolonged period of fighting might perhaps also have caused the death of both gynes within three weeks. In nature, escalation of fights might be avoided by emigration. However, field data suggest that in $L$. gredleri mutilations during dominance interactions also occur in natural nests (Heinze and Lipski 1990).

How do potential queens recognize each other, and how is rank communicated? Detailed analyses of videotaped queen interactions and especially of the initial phase of an attack allowed a first attempt towards these questions. It appears that at least when individuals are highly agitated due to earlier fights with rival gynes, direct antennal contact is not required to release an assault. This does not necessarily imply that cues other than body surface pheromones are involved in the identification of a certain opponent. Queen QA indiscriminately launched attacks on nearby moving ants. Aggression typically ceased after short, probably inspective antennation bouts, but was continued when the attacked individual was $\mathrm{QB}$, or when an antennated worker herself started to bite. Thus, the recognition of personal or rank specific characteristics is involved in domination, but antennations appear to be randomly initiated.

Future investigations will help to explain the formation of hierarchies and the role of fighting in the maintenance of functional monogyny.

\section{SUMMARY}

Colonies of the holarctic ant Leptothorax (s.str.) acervorum from Alaskan shrub tundra habitats are facultatively polygynous; 
however, aggression among female reproductives occurs and might occasionally lead to functional monogyny. High-ranking gynes are highly mobile and initiate attacks randomly, without having exact knowledge on the identity of the opponent, but recognition of individual or rank specific characteristics appears to be involved in the continuation of assaults.

\section{ACKNOWLEDGEMENTS}

Experiments in the laboratory were supported by a DFG Leibniz grant to B. Hölldobler. Thanks are due to J. Liebig and G. Rauch for help in gathering ethogram data, to C. Peeters, B. Hölldobler and N. Lipski for comments on earlier drafts of this manuscript, to A. Buschinger for confirming species determinations, and to M.G. Nielsen for providing Leptothorax from his Alaska collection.

\section{REFERENCES}

ARNOLDI, K. V.

1968. Zonal geographic and ecologic features of myrmecofauna and the ant population of the Russian plain. Zool. Zh. 47: 1155-1178. (in Russian)

Berman, L., Zhigulskaya, Z. A., AND LeyrikH, A. N.

1980. Biological and ecological peculiarities of ants at the upper limit of their distribution in the Bolshoi Annachag mountain ridge. In: The mountain tundra of the Bolshoi Annachag mountain ridge (Upper Kolyma). Vladivostok, p. 110-127. (in Russian)

Bourke, A. F. G.

1991. Queen behaviour, reproduction and egg-cannibalism in multiple-queen colonies of the ant Leptothorax acervorum. Anim. Behav. 42: 295-310.

BROWN, W. L.

1955. The ant Leptothorax muscorum (Nylander) in North America. Ent. News 66: 43-50.

BusCHINGER, A.

1968. Mono- and Polygynie bei Arten der Gattung Leptothorax Mayr (Hymenoptera, Formicidae). Ins. Soc. 15: 217-226.

1973. The role of daily temperature rhythms in brood development of ants of the tribe Leptothoracini (Hym.; Formicidae). In: Wieser W. (ed.) Effect of temperature on ectothermic organisms. Springer, Berlin, Heidelberg, New York, pp. 229-232.

1974. Experimente und Beobachtungen zur Gründung und Entwicklung neuer Sozietäten der sklavenhaltenden Ameise Harpagoxenus sublaevis (Nylander). Ins. Soc. 21: 381-406.

1979. Functional monogyny in the American guest ant Formicoxenus hirticornis (Emery) (=Leptothorax hirticornis) (Hymenoptera, Formicidae). Ins. Soc. 26: 61-68. 
Buschinger, A., AND Alloway, T. M.

1978. Caste polymorphism in Harpagoxenus canadensis M. R. Smith (Hym., Formicidae). Ins. Soc. 25: 339-350.

BusChinger, A., AND WINTER, U.

1976. Funktionelle Monogynie bei der Gastameise Formicoxenus nitidulus (Nyl.) (Hym., Formicidae). Ins. Soc. 23: 549-558.

Carlin, N. F., Hölldobler, B., and Gladstein, D. S.

1987. The kin-recognition system of carpenter ants (Camponotus spp.). III. Within colony discrimination. Behav. Ecol. Sociobiol. 20: 219-227.

Collingwood, C. A.

1979. The Formicidae (Hym.) of Fennoscandia and Denmark. Fauna Entomol. Scand. 8. Scan. Science Press Ltd., Klampenborg, Denmark. pp. 174.

Douwes, P., Sivusaari, L., Niklasson, M., and Stille, B.

1987. The relatedness among queens in polygynous nests of the ant Leptothorax acervorum. Genetica 75 : 23-29.

FRANCOEUR, A.

1983. The ant fauna near the tree-line in northern Québec (Formicidae, Hymenoptera). Nordicana 47: 177-180.

GREGG, R. E.

1972. The northward distribution of ants in North America. Can. Ent. 104: 1073-1091.

HEINZE, J.

1989. A biochemical approach toward the systematics of the Leptothorax "muscorum" group in North America (Hymenoptera: Formicidae). Biochem. Syst. Ecol. 17: 595-601.

1990. Dominance behavior among ant females. Naturwissenschaften 77: 41-43.

1991. Koloniegründung in der Kälte: Strategien von Ameisenweibchen in borealen Habitaten. Verh. Dtsch. Zool. Ges.

HEINZE, J., AND BUSCHINGER, A.

1988. Polygyny and functional monogyny in Leptothorax ants (Hymenoptera: Formicidae). Psyche 95: 309-325.

HEINZE, J., AND LIPSKI, N.

1990. Fighting and usurpation in colonies of the palaearctic ant Leptothorax gredleri. Naturwissenschaften 77: 493-495.

HeInZE, J., AND SMith, T. A.

1990. Dominance and fertility in a functionally monogynous ant. Behav. Ecol. Sociobiol. 27: 1-10.

Iто, F.

1990. Functional monogyny of Leptothorax acervorum in northern Japan. Psyche 97: 203-211.

KUTTER, $\mathrm{H}$.

1977. Formicidae. In: W. Sauter (ed.) Insecta Helvetica: Fauna 6. Schweizer. Entomol. Ges., Zürich, pp. 298.

NIELSEN, M. G.

1987. The ant fauna (Hym., Formicidae) in Northern and Interior Alaska. A survey along the Trans-Alaskan Pipeline and a few highways. Ent. News. 89: $74-88$. 
Rissing, S. W., AND PolLOCK, G. B.

1988. Pleometrosis and polygyny in ants. In: R. L. Jeanne (ed.) Interindividual behavioral variability in social insects. Westview Press, Boulder, CO. p. 179-222.

Stille, M., Stille, B., AND Douwes, P.

1991. Polygyny, relatedness and nest founding in the polygynous myrmicine ant Leptothorax acervorum (Hymenoptera; Formicidae). Behav. Ecol. Sociobiol. 28: 91-96. 

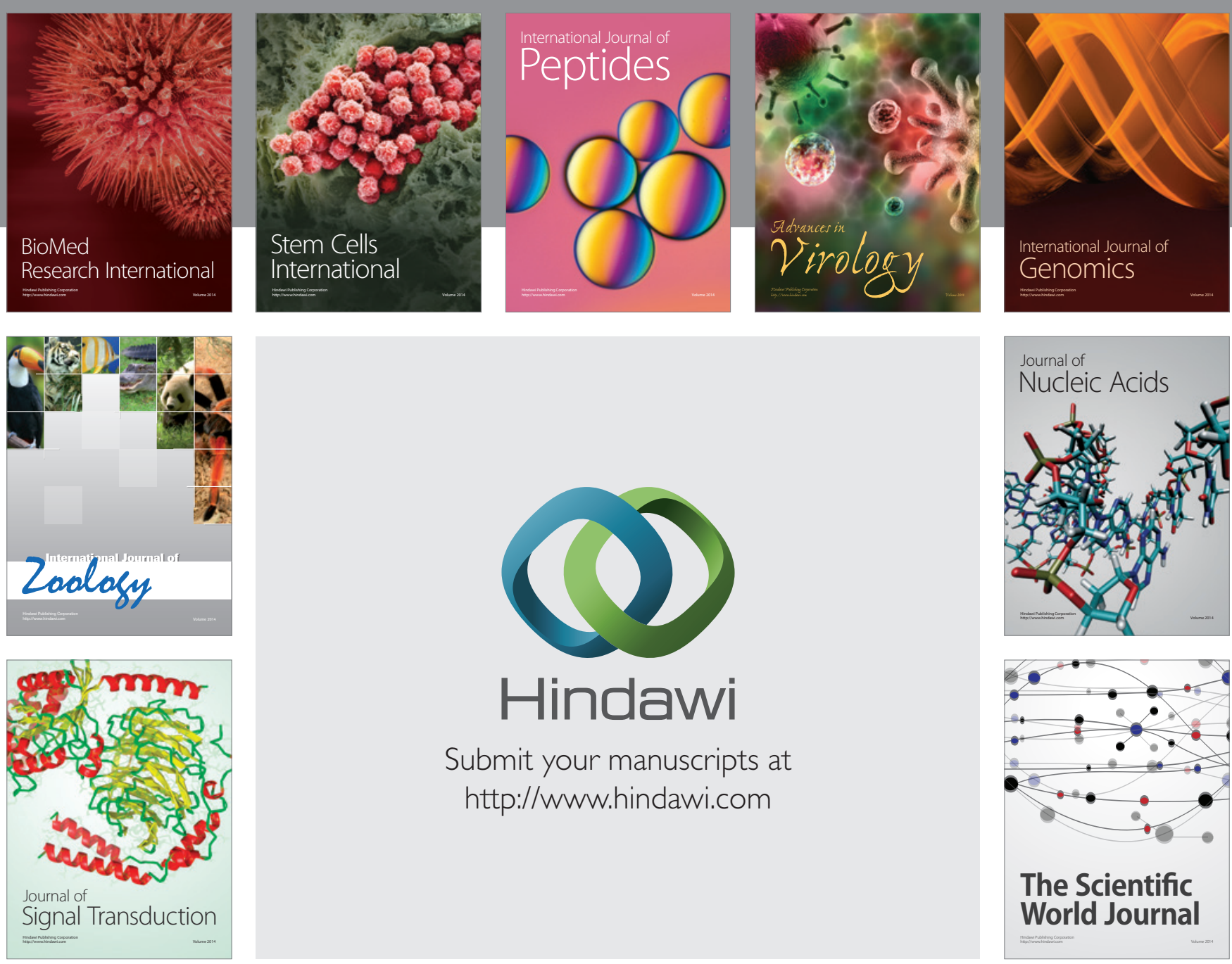

Submit your manuscripts at

http://www.hindawi.com
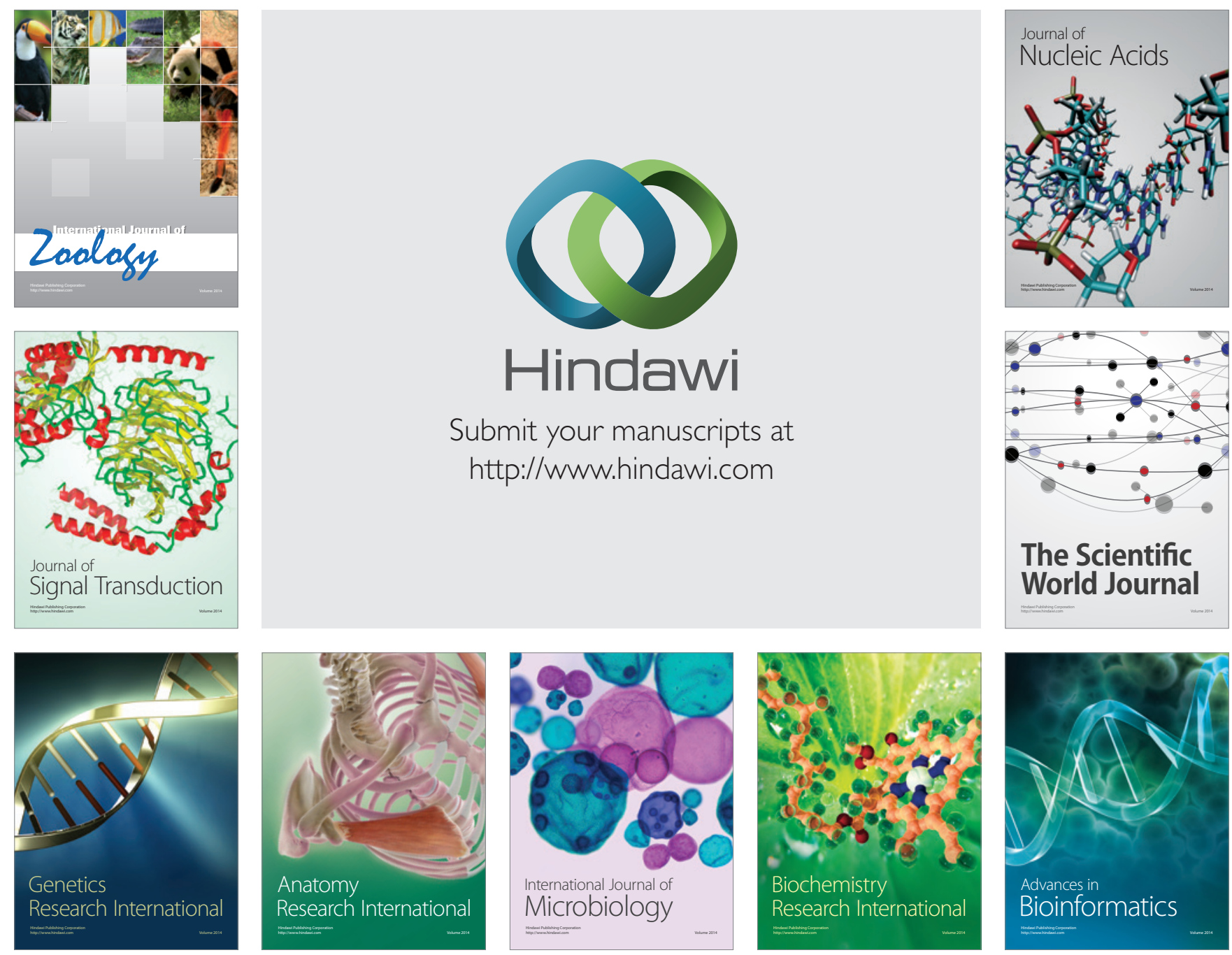

The Scientific World Journal
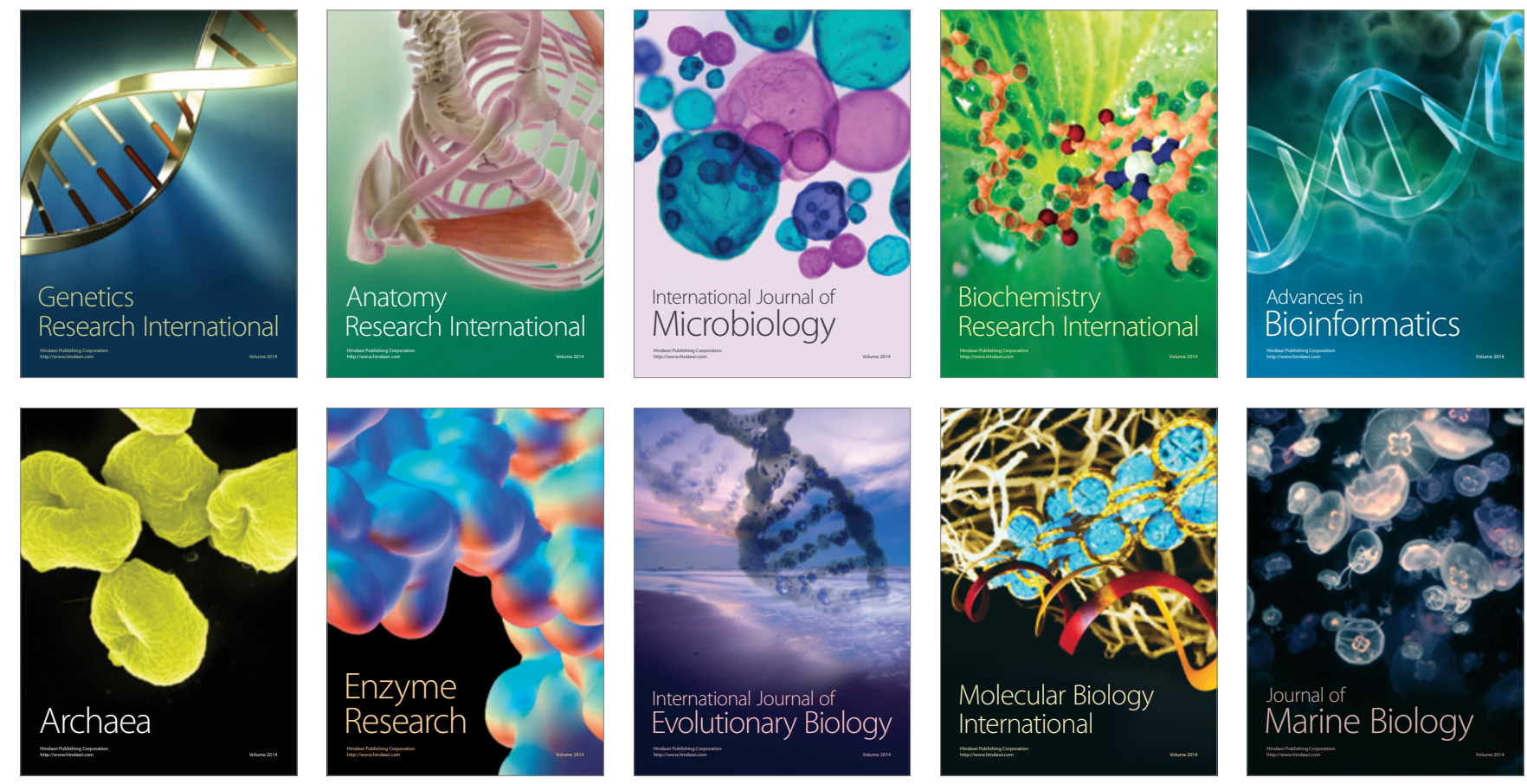